\title{
Space Research in Tartu at the Beginning of the Cosmic Era
}

\author{
Valdur Tiit \\ Estonian Euromanagement Institute, Estonia
}

Copyright $(\mathcal{C} 2015$ by authors, all rights reserved. Authors agree that this article remains permanently open access under the terms of the Creative Commons Attribution License 4.0 International License

\begin{abstract}
The paper gives an overview of the scientific results achieved by the Tartu Observatory. The main emphasis is on the works of the Department of Equipment Development and its participation in the research programmes of the Soviet Union during the initial years of the space era. The results in building radiation detectors and in particular creating new spectral devices for the usage of short-wave ultraviolet radiation in scientific research are presented. The story of the world's first orbital astronomical observatory with several telescopes is explained. Additionally the two orbital radiometers working in the ultraviolet range of the spectrum that were built in Tartu and applied with success for the research of the Earth's atmosphere and the Moon's radiation are described. The article also touches upon the creation of pulsed synchrotron.
\end{abstract}

Keywords Ultraviolet Radiation, Detector, Device for Cosmic Investigations, Vacuum Monochromator, Radiometer, Pulsed Synchrotron

\section{Introduction}

Scientists at the Tartu Observatory gave a significant contribution to the development of astronomy during the 130 years prior to the WW II. After the war, there were still astronomers in Tartu who were keen to continue the development. They initiated the building of a new observatory and equipping it with contemporary telescopes and other devices. The dawn of space era in fall 1957 when the Soviet Union sent the world's first artificial astral body Sputnik 1 to orbit the Earth opened up opportunities for space research outside the Earth's atmosphere. This gave a new impulse to the scientific establishments in Tartu to further research in astronomy and physics. In order to realise the plans, a new structural unit was set up with the main tasks of assembling devices for space research and making the new, still missing parts as well as building an equipment technical control base. Since industrial manufacturing was non-existent, the unit developed and made new vacuum ultraviolet radiation receivers and spectral devices for studying them. The paper gives an overview of these activities that spanned over a course of 35 years.

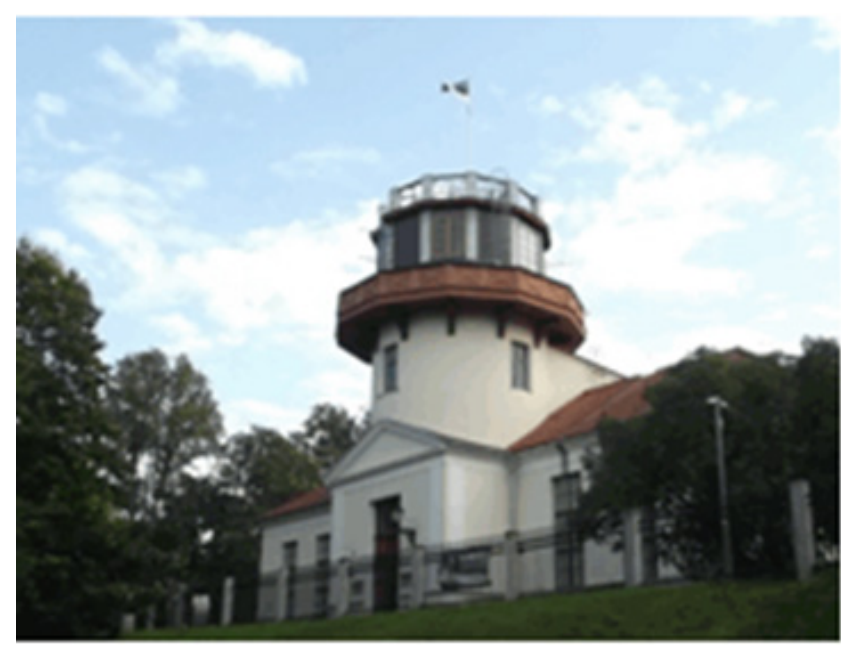

Figure 1. The old Tartu Observatory.

\section{A Glance at the History}

For millennia the starry sky and the phenomena occurring in the sky have been of great interest to man. The initial understanding of the Earth being the centre point of the Universe has long been clarified. It is clear that the Earth is merely a tiny and insignificant astral body in the vast cosmos. However to all living creatures here, it is of utmost importance. It is also important for the people living on the Earth to know what goes on in the surrounding cosmos.

The Tartu Observatory has given a notable contribution to space research over a long period of time; it was founded in 1808-1812 as part of the University of Tartu (founded in 1632) and is based in Tartu, which is a small Estonian town with nearly a thousand year old history and a population of a hundred thousand. At the time Estonia was a province in the Czarist Russia (the Republic of Estonia was established after the Independence War in 1918-1920 and regained its 
independence in 1991 after the collapse of the Soviet Union). A view of the old Tartu Observatory can be seen on Figure 1.The famous Russian astronomer and geodete of German origin Friedrich Georg Wilhelm von Struve was the director of the Tartu Observatory in 1820-1839. In $1824 \mathrm{~W}$. von Struve bought a 9-inch Fraunhofer refractor (telescope), which was the largest refractor in the world at the time (Figure 2). In $1837 \mathrm{~W}$. von Struve was the first person to measure the distance of another star - Vega in the constellation Lyra - from the solar system. The result of his measurements at the time was 26.1 light years, the result measured a few years ago is 25.3 light years [1].

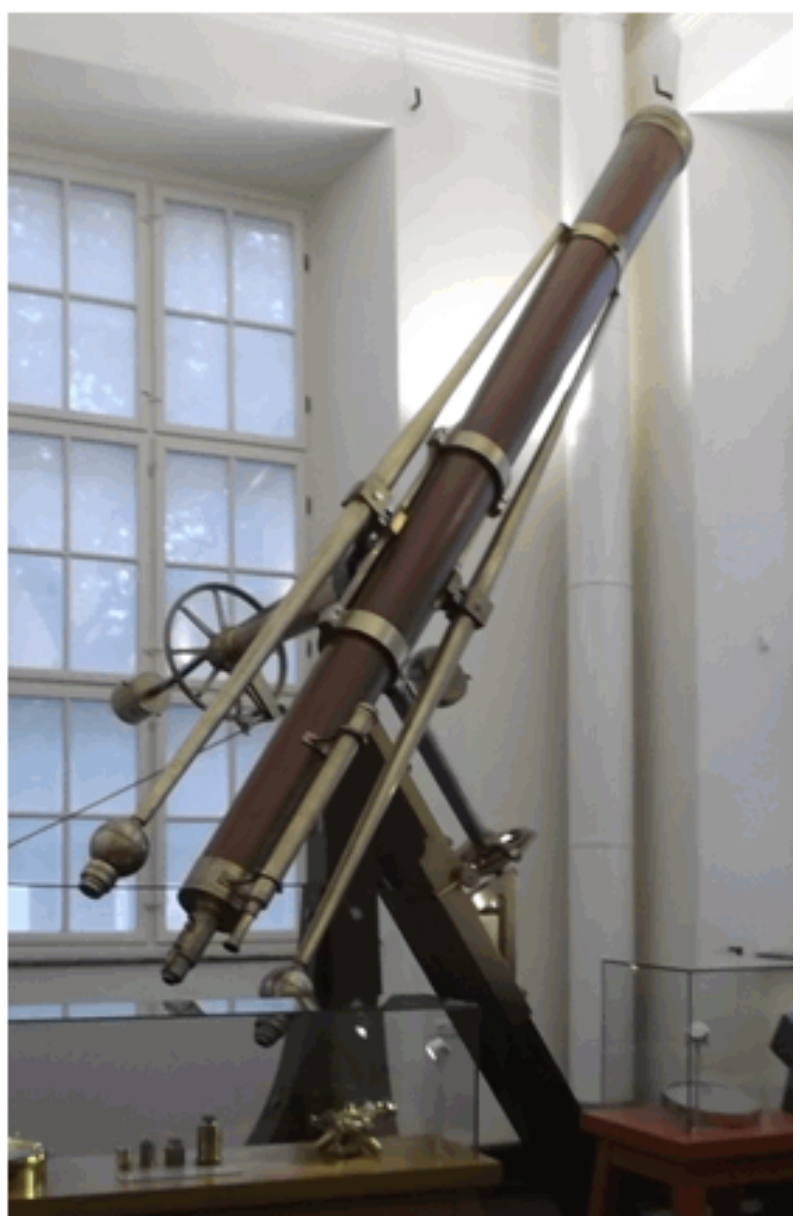

Figure 2. The Fraunhofer's large refractor.

The famous Estonian astronomer Ernst Julius Öpik worked at the Tartu Observatory before WWII, he had to flee Estonia in 1944 and worked abroad for the rest of his life. In 1918-1922 E. J. Öpik created the method for determining the distance of extragalactic spiral nebulae and in 1922 was the first in the world to fairly accurately measure the distance to island universe Andromeda (at the time he concluded the distance to be $450 \mathrm{kpc}$, the most recent estimate is $778 \mathrm{kpc}$ (2.54 million light years)) [2]. Possibly his most significant study was on the evolution of stars, published in 1938. According to this theory hydrogen turns to helium during the thermonuclear reaction happening on the Sun and other stars. In approximately five billion years the properties of the Sun will change drastically and it's increased radiation will destroy life on the Earth. Very sad !

Although WWII destroyed half of the town of Tartu, it left the Tartu Observatory intact. The light from the town as it was being rebuilt started to interfere with astronomical observations. Therefore in spring 1953 a decision was taken by the director of the Institute of Physics and Astronomy of the Academy of Sciences of the Estonian SSR (IPA) Aksel Kipper and supported by the Academy of Sciences of the Estonian SSR and the main organisation of astronomers in the Soviet Union the Astronomical Council of the Academy of Sciences of the Soviet Union to build a new observatory $20 \mathrm{~km}$ from Tartu (the Tartu Observatory, completed in 1964, (Figure 3)).

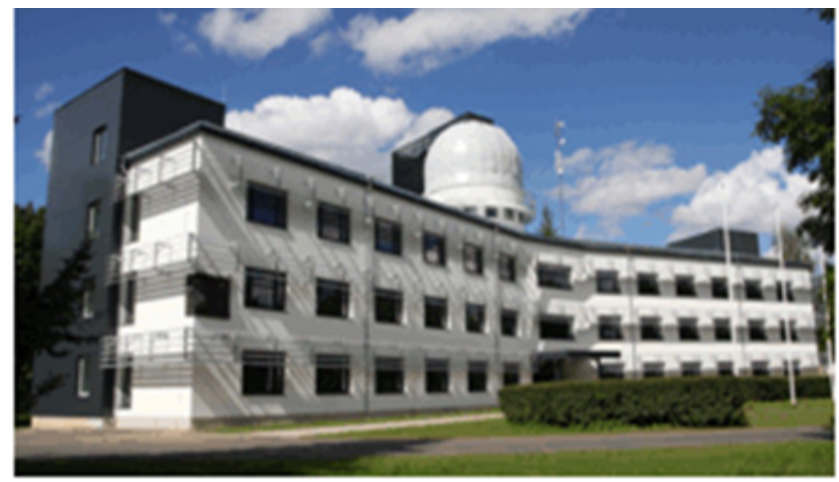

Figure 3. The main building of the new Tartu Observatory in 2014.

The author started to work for the above-mentioned institute in the same year while still a student. In 1955 I graduated from Tartu State University (TSU) with distinction and continued my work as a young scientist on the theory of radiation of the planetary nebulae. But Life seemed to have other plans for me. As part of the International Geophysical Year the Soviet Union was making preparations without much prior talk about it to send a man-made satellite to orbit the Earth. To monitor the flight, several observation stations across the Soviet Union were set up, equipped with small optical telescopes. For that reason in the spring of 1957 I was sent on a special course to a small mountain resort near Ashgabat (Turkmenistan). Upon completing the course, the rector of TSU Fyodor Klement appointed me as the executive manager of the satellite observation station in Tartu. I organised the building of a pavilion for telescopes of the observation station and by including students I put together the observation team. With the financial support from the Council of Ministers of the Estonian SSR and TSU everything went smoothly. Before long the new station was needed. On October 4th, 1957 the Soviet Union successfully launched the first ever satellite to orbit the Earth (Figure 4)! It became famous by the Russian name Sputnik.

People were extremely interested in Sputnik 1 . To make the times suitable for observations public, I suggested that the Estonian Radio would broadcast the information together with daily news. It was done for years and perhaps it was the 
only place in the world that did it.

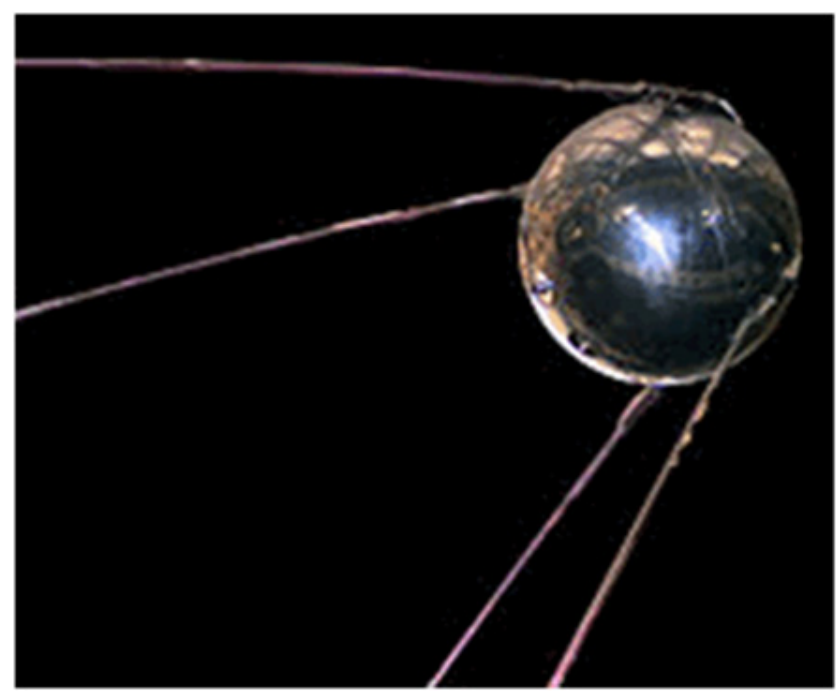

Figure 4. The world's first artificial satellite Sputnik 1.

In Tartu we proposed that the satellite should be named lunoid, but the beautiful word remained in the shadow of the greater events. However, it is occasionally used in Estonia.

So with huge international sensation the fall of 1957 saw the birth of the space era, which despite some adversities has thus far been a great success and will undoubtedly remain one of the key activities of mankind.

\section{Detectors and Spectral Devices}

In 1959 the IPA set up the Department of Equipment Development (DED) as a part of its astronomical unit and I was appointed by the director to be the head of the laboratory. The initial task was to facilitate the development of experimental works at the new observatory. But before long the freshly born space era channelled our attention to new opportunities to measure the short-wave vacuum ultraviolet radiation outside the interfering impact of the Earth's atmosphere. Measuring such radiation in space called for the development of completely new devices, including acquiring necessary detectors as well as preparing a technical control base. The situation with electronic schemes was easy, but very difficult with detectors. As it transpired, such detectors were not yet being manufactured in the Soviet Union, nor in the rest of the world. We were left with the only realistic option - based on the idea generated by the United States researchers Talbot Albert Chubb and Herbert Friedman [3] our laboratory itself started to make photon counting devices for VUV spectral range $105-180 \mathrm{~nm}$. We devised them in various shapes and with different filling gases according to the plan of the experiment (Figure 5). It later turned out that the same task was tackled by Leonid S. Sorokin in the Moscow Institute of Vacuum Technique (based on private information) with whom the collaboration flourished over the years to come.

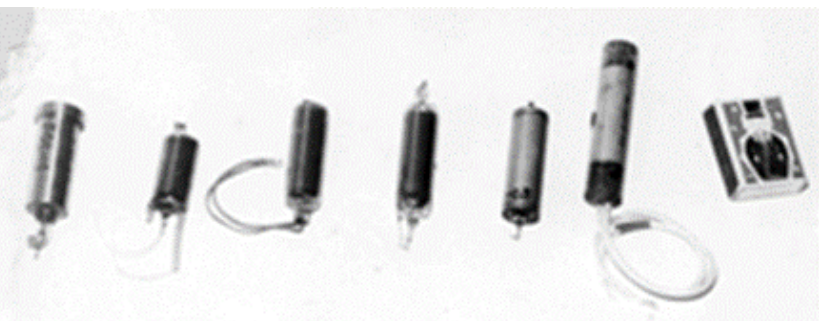

Figure 5. The photon counters made in the DED.

During the summer of 1962 the new Tartu Observatory that was being built and our laboratory hosted a group of well-known scientists among whom were the vice chairman of the Council of Astronomy Alla G. Massevich, the vice president of the Academy of Sciences of the Estonian SSR Gustav Naan, famous physicists Yakov B. Zeldovich and Bruno Pontecorvo. B. Pontecorvo was a passionate underwater swimmer and our handymen made a balancing tin weight for him to swim in the nearby lake. They also paid a visit to our home and signed the guestbook (Figure 6).

To study the spectral properties of the new VUV radiation detectors, we needed an appropriate vacuum VUV monochromator. Unfortunately at the time such unique spectral devices were still very rare in the Soviet Union and only a few bigger research institutes such as the S. I. Vavilov State Optical Institute (SOI) in Leningrad (now St Petersburg) and Leningrad State University had them.

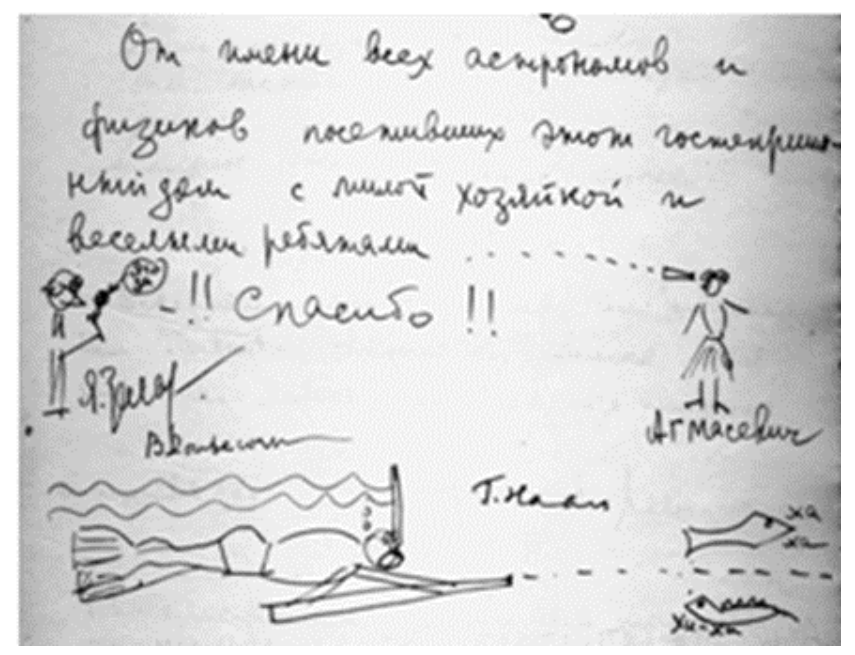

Figure 6. Famous scientists in Tartu. The signatures of Y. B. Zeldovich, B. Pontecorvo, A. G. Massevich and G. Naan.

We decided to build our own device, although nobody in our young team nor anyone in Estonia had any experience in developing spectral devices. Therefore it was psychologically understandable that we came across harsh sceptic opposition of many older colleagues in the institute. Despite all this we proceeded with great enthusiasm. As an optical scheme we chose a relatively simple, but good version proposed by P. D. Johnson [4] and made the whole construction as simple as possible. For example we placed the main part of the monochromator on the table in the 
laboratory and fitted the rotary vane pump together with vacuum valves into it. The Rowland type concave diffraction grating with a curvature radius of $1 \mathrm{~m}$ and number of grooves 600 per $\mathrm{mm}$ was made for us in the S. I. Vavilov State Optical Institute. Everything worked out well and already within a couple of months, in October 1964 our device was ready (Figure 7) and started working as envisaged [5]. Later on we added a proper metal base for our first great vacuum monochromator.

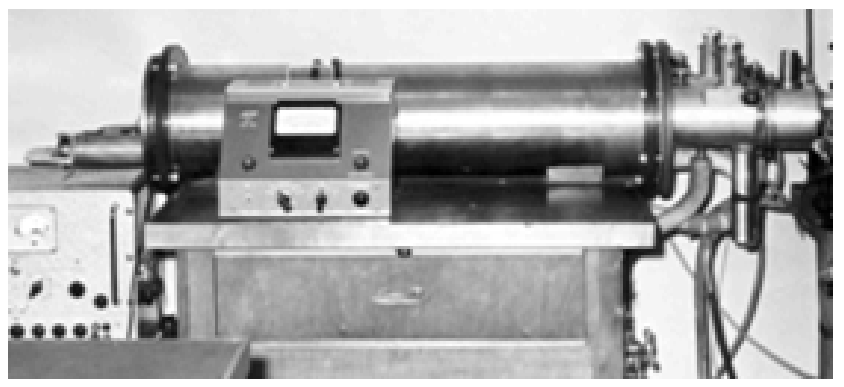

Figure 7. The vacuum monochromator DVM-1 for vacuum ultraviolet range constructed in the DED.

As a radiation source in front of the entrance slit of the vacuum monochromator we used high voltage gaseous discharge in hydrogen, which is a good solution in many cases. To automate the measurements we slightly altered the scheme of the industrial recorder so that it worked as a simple analogue computer that performed the division operation. We sent the photon counter measuring signal as one input, the numerator and as the denominator the second signal from the reference detector, the photomultiplier equipped with sodium salicylate screen. Since sodium salicylate has a constant quantum efficiency in the spectral range of 105-180 nm, we had the spectral efficiency of the photon counter on the paper tape of the recorder already in the same units.

Unfortunately our joy was incomplete. The experiments demonstrated that our ordinary vacuum monochromator's output radiation at the right wavelength contains approximately 10 power -4 part scattered radiation from other parts of the spectrum. This figure was too high for accurate measurements of the "tail" of the photon counters spectrums. Therefore in 1965 we decided to build an ultraviolet radiation double vacuum monochromator, using the same optical scheme twice in a row. This time we also used the Rowland type concave diffraction gratings made for us in the SOI, but in the interest of compactness the curvature radius was $0.5 \mathrm{~m}$ and the number of grooves 1200 per $\mathrm{mm}$. For the purposes of safety we constructed the double vacuum monochromator in a way as if it was composed of two onetimes. The results were great and the new spectral device started to operate in summer $1966[6,7]$. With this device the spectral resolution of $0.03 \mathrm{~nm}$ was reached. Measurements indicated that the output radiation of the double vacuum monochromator contains just 10 power -9 part scattered radiation from other parts of the spectre. This was a good result and enabled precise research of photon counters spectres as well as new research in experimental physics.

Based on the literature available to us and private information it turned out that we had built and activated the first working VUV double vacuum monochromator with diffraction gratings for the spectrum range of 100-220 nm (main working range) in the world (Figure 8 ). Thus we were the only laboratory in the world working with such a unique spectral device and remained as the support centre in the Soviet Union for calibrating space equipment when measuring VUV radiation.

In the later years we improved the construction of vacuum monochromators and built them for several other scientific establishments in the Soviet Union (Figure 9).

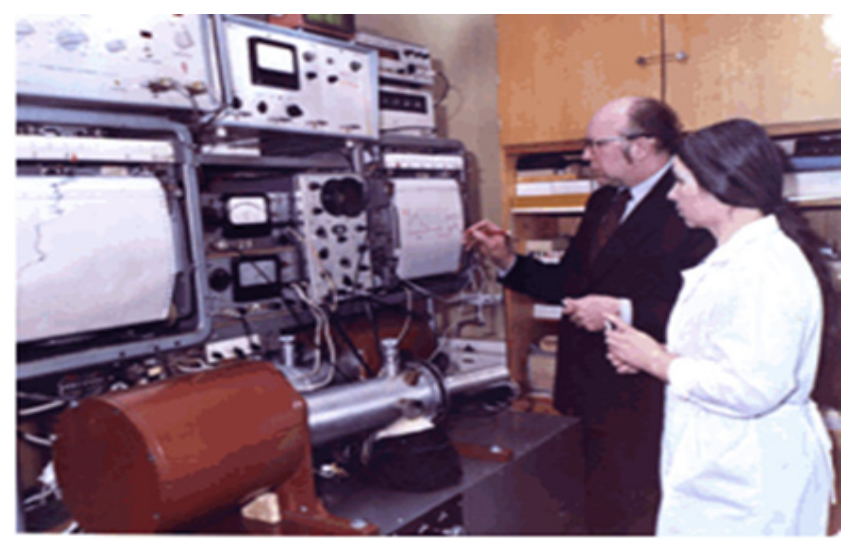

Figure 8. The world's first double vacuum monochromator with diffraction gratings for ultraviolet range constructed in the DED. On the photo Valdur Tiit and his colleague Rimma Šatskina.

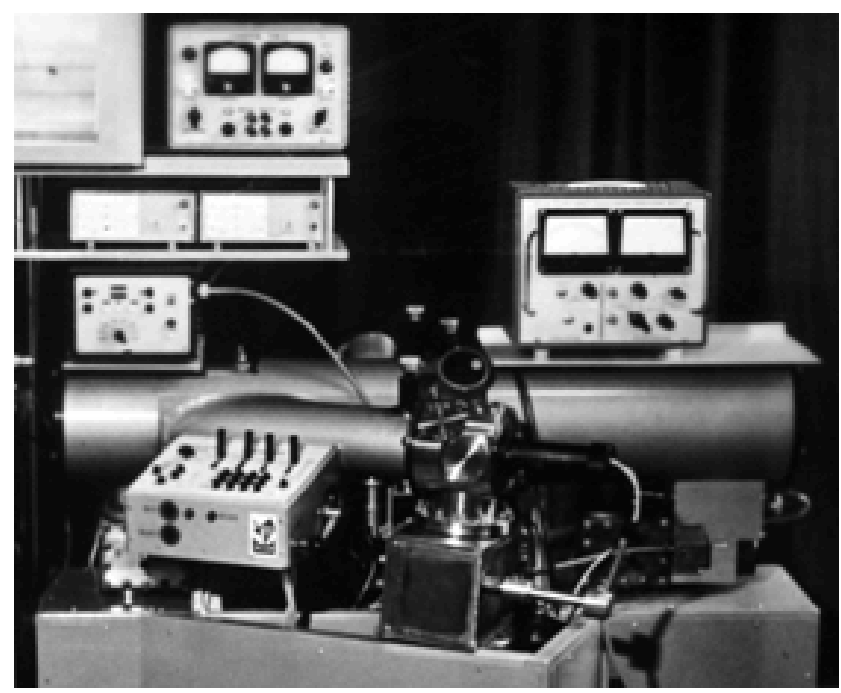

Figure 9. The double vacuum monochromator TVM-8 with diffraction gratings for ultraviolet range constructed in the DED.

\section{The First Space Experiments in Collaboration with Other Observatories}

To actually embark on space research and find necessary 
collaborators the Institute of Physics and Astronomy turned to the Council of Astronomy with apposite proposals. Pursuant to the information received we started our communication with the Byurakan Astrophysical Observatory (BAO) in Armenia. I visited the famous observatory, located in the mountains, a few dozen kilometres from the capital Yerevan. We had numerous discussions with Grigor A. Gurzadyan on various space projects, including the measurements of VUV radiation. Already then he proposed the idea of taking a big telescope to the Moon, which seemed like a better option than a good orbital telescope. G. A. Gurzadyan and his wife also visited Tartu and our home. As a memento of this very pleasant meeting there is a drawing by him in our guestbook of a view from the observatory to Mount Ararat, which is in Turkey (Figure 10). Unfortunately due to various technical circumstances the collaboration with the $\mathrm{BAO}$ was never realised.

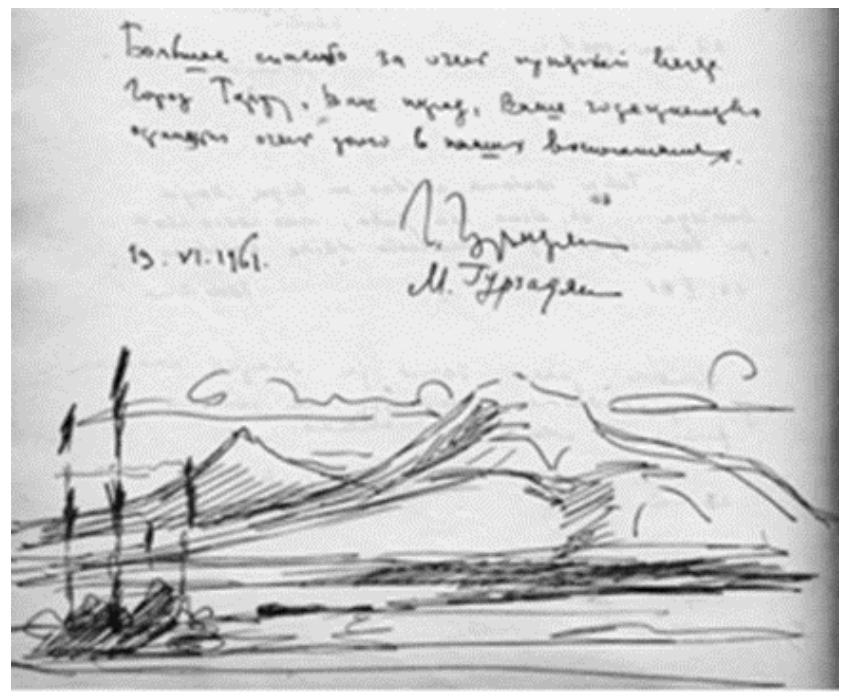

Figure 10. A drawing by G. A. Gurzadyan of the Mount Ararat in our family guestbook.

Our collaboration with the Crimean Astrophysical Observatory (CrAO) was more fruitful. The director of the observatory Andrei B. Severny supported the co-operation and hence it was agreed that we will make the photon counters and the laboratory of Andrey V. Bruns will be in charge of the planning of the experiments, the mechanical and electrical part of the equipment. This is how the cosmic VUV radiation using vertical rockets was measured for probably the first time in the Soviet Union in collaboration between the two observatories. We used photon counters with various spectral sensibilities, including those that registered practically only hydrogen main radiation Lyman- $\alpha$ line at wavelength $121.6 \mathrm{~nm}$.

The long-term collaboration with the Moscow Šternberg Astronomical Institute, MŠAI was very successful. Vladimir G. Kurt and his colleagues were very enthusiastic to apply new options in cosmic astronomical studies. They mostly implemented the photon counters made in the Moscow
Institute of Vacuum Technique, but we studied and calibrated them. Their experiments on interplanetary stations Venus- 4 , Venus-5 and Venus-6 [8,9] are most notable.

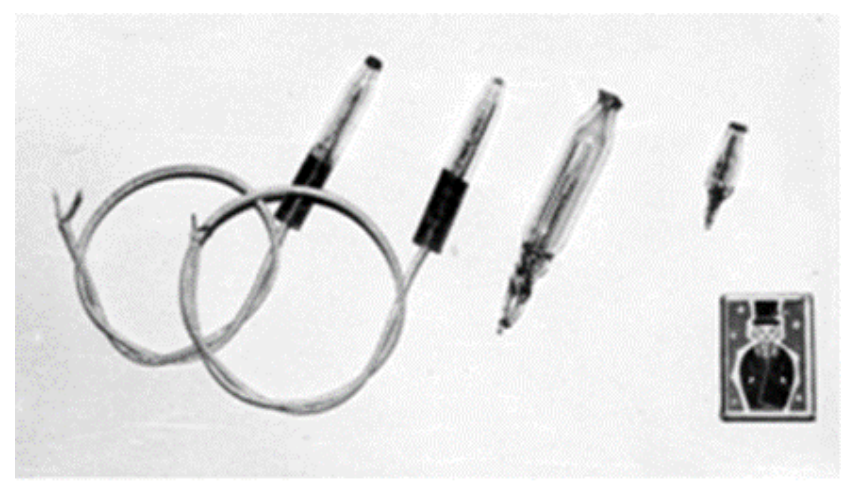

Figure 11. Control lamps for the world's first orbital astronomical observatory made in the DED.

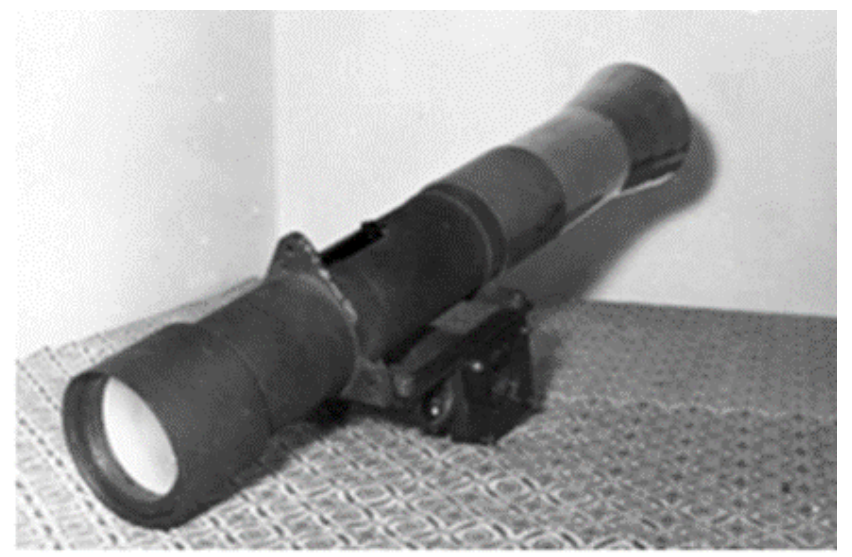

Figure 12. Telescope for VUV radiation of the world's first orbital astronomical observatory.

Pursuant to the proposal of the IPA the Council of Astronomy summoned a significant meeting at the beginning of the 1960s in Moscow to discuss a big space project presented by our laboratory. World-famous astronomer, the director of BAO Victor A. Ambartsumian, chaired the meeting. It was attended by numerous famous scientists from the Soviet Union, including the director of MŠAI Dmitrii J. Martynov, the head of the laboratory Iosif S. Šklovski and researcher V. G. Kurt, the director of CrAO A. B. Severny, the famous optical scientist Vladimir K. Prokofiev, G. A. Gurzadyan from BAO and several other specialists in the field. Since I had to make the keynote speech, the high-level assemblage of scientists made me quite nervous. During the speech I proposed that within foreseeable future an orbital astronomical satellite should be built that has small telescopes (with mirror diameter $6-10 \mathrm{~cm}$ ) measuring radiation in the roentgen range of star spectre, VUV range and long wave ultraviolet radiation. All the astronomical measuring equipment had to be rocketed to the Earth's orbit. The discussion was copious and as a result, it was decided to form a team with people from IPA, MŠAI and CrAO to effectuate the project. Pursuant to the recommendation of $\mathrm{V}$. 
G. Kurt the Moscow-based All-Union Research Institute of Scientific Instruments (MIS) was also included during a later stage to make the mechanical and electronic parts. The representatives of our laboratory participated in all the important discussions and the conclusive consultation took place in the new Tartu Observatory in the winter of 1965. The main role of our laboratory was to make the VUV photon counter with some specific particulars, to calibrate all the VUV detectors and to make and study the stability of the small control lamps (Figure 11) of the telescopes. In total the astronomical satellite had one roentgen range receiver, five VUV (Figure 12) and two UV range telescopes. CrAO made the latter.

The power supply was battery based, as suitable photo voltage panels were not yet available. Together with representatives from all the above-mentioned institutes and with a colleague Riho Nymmik (now a well-known space scientist in Moscow) we went to the cosmodrome in Kapustin Yar in April 1968. There I was appointed to lead the group of scientists. The task of the team was the final pre-launch control of all the equipment of the astronomical satellite. We succeeded at our task and on April 18, 1968 a powerful rocket took satellite Cosmos-215 to the Earth's orbit. Upon receiving the information from the observation stations that all the equipment on the orbital astronomical observatory works without a glitch, we were relieved from tenterhooks and greatly overjoyed. The equipment with a scientific task worked for approximately one month until the batteries were depleted [10].

It later transpired that the US had launched a satellite Orbiting Astronomical Observatory OAO-1 with similar tasks approximately two years earlier, but due to serious technical errors the equipment never started to operate [11]. A much-improved OAO-2 was launched by the US later than Comos-215, on December 7, 1968 and it worked according to plan [12]. Hence, the scientific equipment on Cosmos-215 should be regarded as the world's first successfully operating orbital astronomical observatory.

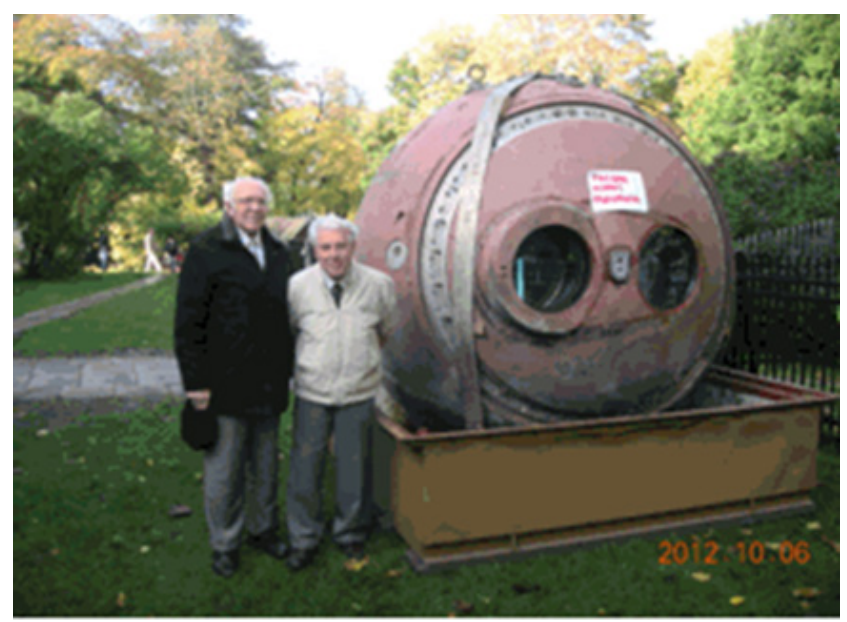

Figure 13. Russian spacecraft returned from the orbit near the old Tartu Observatory. On the photo Valdur Tiit and a space technology hobbyist Harri Laos.
The 55th anniversary of the launch of the first satellite Sputnik 1 was celebrated in the old Tartu Observatory (now a museum) in the fall of 2012. As part of the celebrations, a Russian spacecraft returned from the orbit was demonstrated (Figure 13).

\section{Orbital Radiometers, Spectral Devices and Pulsed Synchrotron}

In the spring of 1970 in conjunction with the changed nature of work the DED moved from the new observatory to a new building on the outskirts of Tartu and in terms of organisation it was transferred from the Astronomy to the Physics side of the Institute. The first task was to build orbital ultraviolet radiation radiometers to study the atmosphere and the Moon. An institute of applied space studies in Moscow ordered the work. The DED made two types of radiometers. I was the chief constructor of them both. The first, SFM-4UF, which had two telescopes with $9 \mathrm{~cm}$ mirrors in diameter and four photomultipliers as detectors, was controllable by a cosmonaut (Figure 14) [13] the second was an autonomous apparatus RUF (Figure 15).

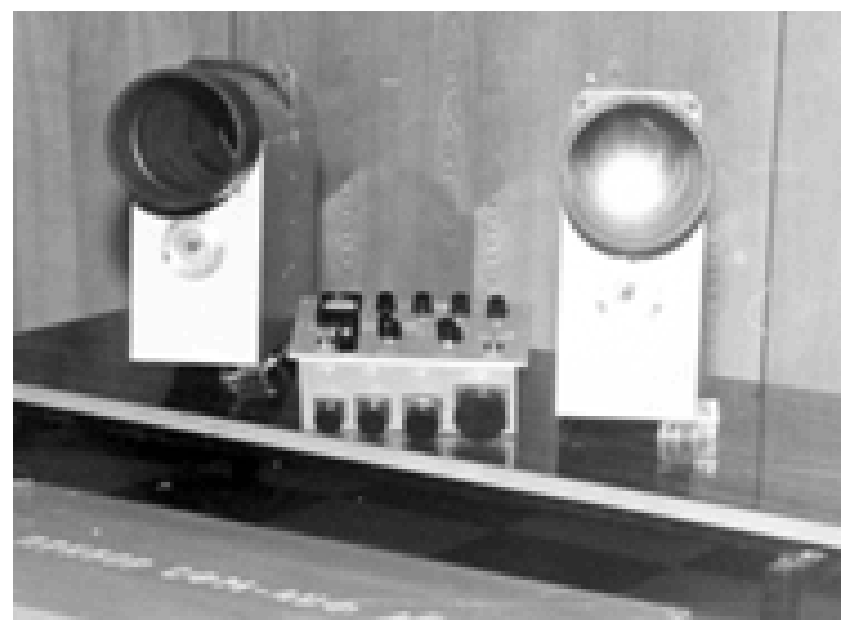

Figure 14. The controllable orbital spectroradiometer SFM-4UF. The console and radiation registration blocks.

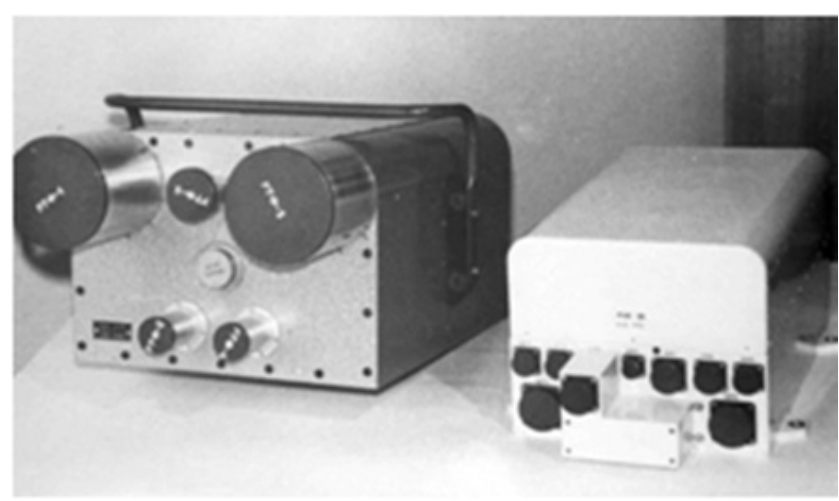

Figure 15. The automatic orbital spectroradiometer RUF.

This apparatus had two telescopes the same size as the first one. The collected radiation was directed at the diffraction 
grating and to convert it into electrical signal forwarded on to the photomultipliers. To enhance the differentiation of single objects the optical scheme contained a fast rotating raster mirror. Two smaller telescopes (with mirror diameter of about $5 \mathrm{~cm}$ ) sent the ultraviolet radiation to the photon counters made by the DED. The Tartu Branch of the Special Construction Bureau of the Estonian SSR Academy of Science (SCBoEAS) made the technical part of the automatic radiometer. The technical tests of radiometer RUF were conducted in high vacuum at temperatures $-50 \mathrm{C}$ to $+50 \mathrm{C}$ (an imitation of space conditions) in a unique stand made by a laboratory of TSU (presided by Arved Tammik).

Both photometers were launched to the Earth's orbit and they worked smoothly. The described radiometers were the last works for the Soviet Union space research that the DED participated in.

The second course of action of our laboratory was perfecting the double vacuum monochromators and the development and building of some earmarked spectral devices. We continued to build different versions of the double vacuum monochromators as several research institutes in the Soviet Union had expressed an interest in buying them. Based on the double vacuum monochromator we succeeded in building a spectrophotometer with a new scheme (Figure 16), which was patented in the USA [14] and France.

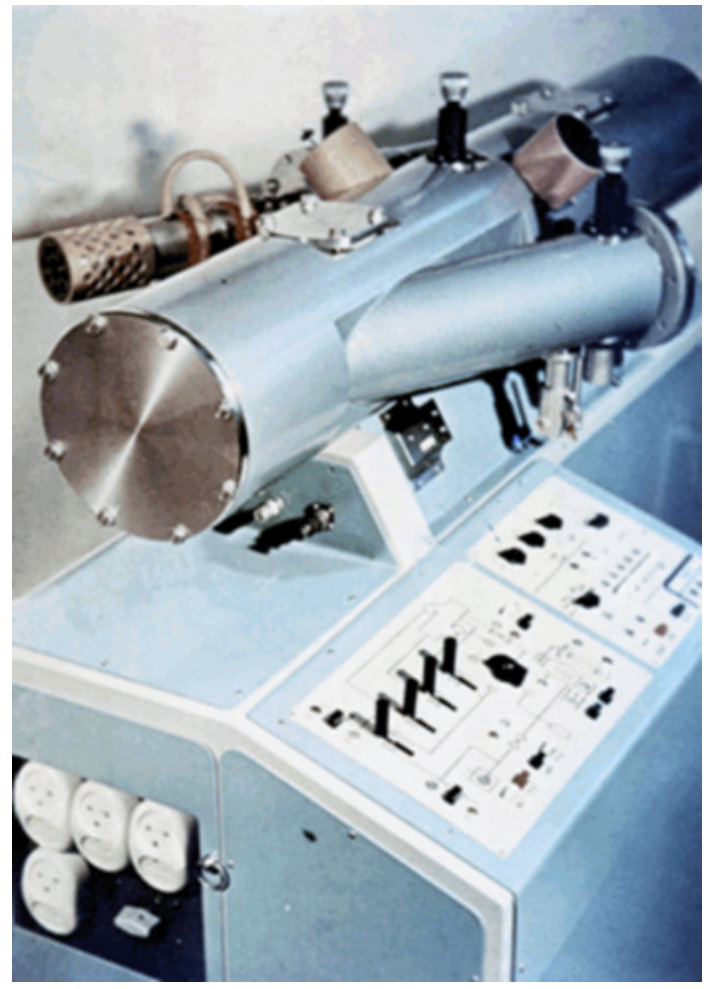

Figure 16. Spectrophotometer for VUV spectral range, based on the double vacuum monochromator TVM-7.

The new spectrophotometer enabled to expand the measuring diapason of the materials with poor transparency by almost a thousand times compared to regular photometers
[15].

We also made a special VUV spectrograph that enabled the registration of up to 10 spectrograms on to one $24 \mathrm{~mm}$ film without opening the vacuum chamber (Figure 17).

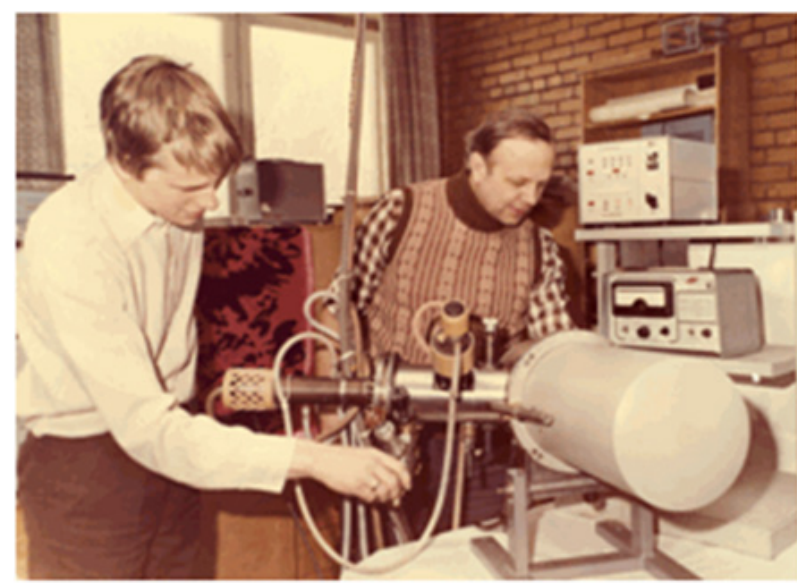

Figure 17. Spectrograph for VUV radiation spectral range. On the photo colleagues Neeme-Rein Elmet and Kalev Pill.

For more simple laboratory experiments we developed a compact VUV radiation vacuum monochromator, which used the diffraction gratings with varying groove increments made by $\mathrm{SOI}(\mathrm{R}=0.5 \mathrm{~m}, \mathrm{~N}=1200 \mathrm{~g} / \mathrm{mm}$ ) (Figure 18) [16].

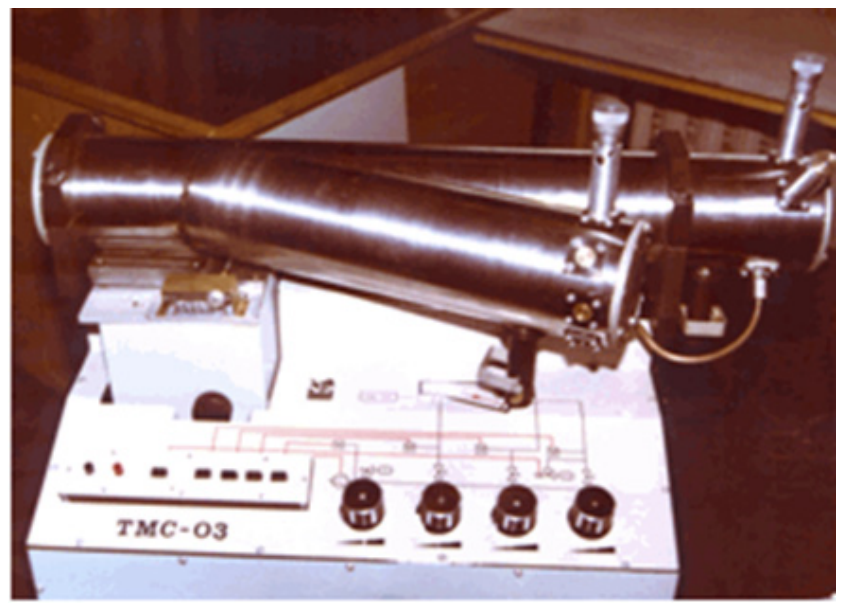

Figure 18. The compact vacuum monochromatotor TMC-03 for vacuum ultraviolet range.

Although high voltage gaseous discharge in hydrogen is a sufficient radiation source in the VUV spectral range in a lot of cases, it is not usable due to band spectrum in devices with greater spectral resolution. Reputedly the spectre of synchrotron radiation is unbroken, but it is usually achieved in big laboratories with big devices. For small physics laboratories pulsed synchrotrons are more feasible, in which the copper wire Helmhotz coils cooled in liquid nitrogen generate a strong magnetic field. In 1986 in co-operation with the Tartu Branch of the SCBoEAS, the SCBoEAS and TSU we managed to successfully start the laboratory pulsed synchrotron LIS-2 (Figure 19), which was granted a Soviet Union patent [17] and described on [18]. 


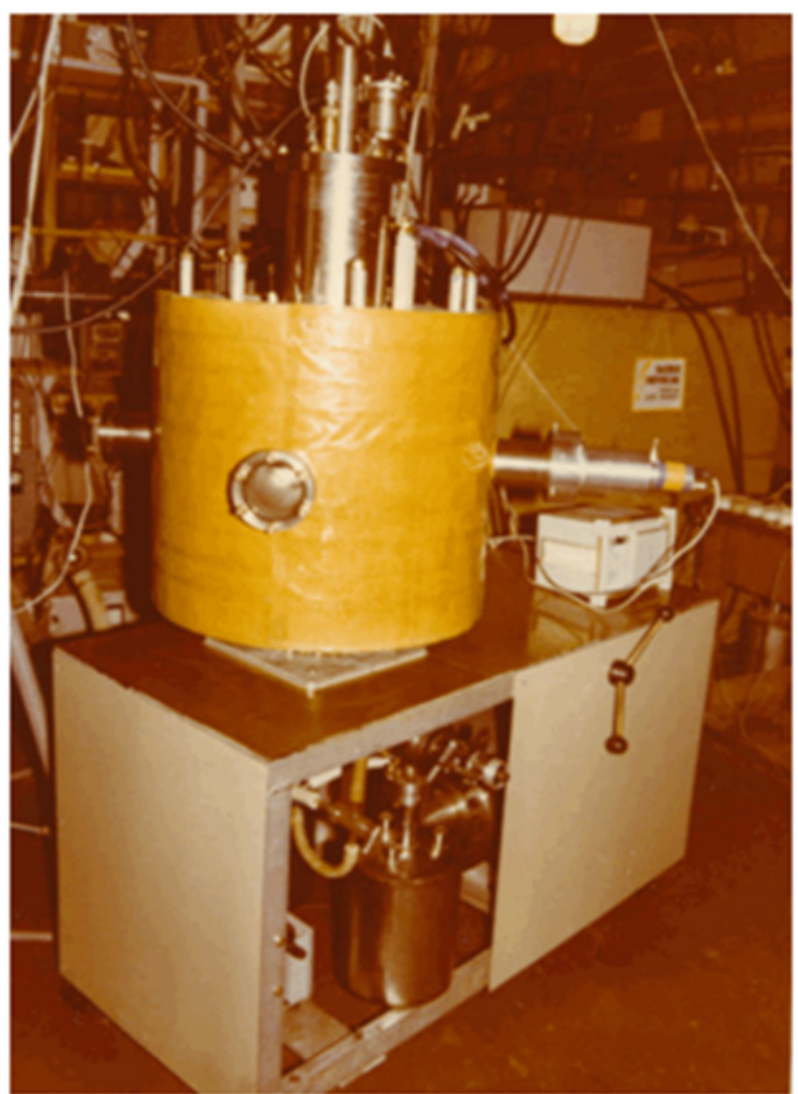

Figure 19. The laboratory pulsed synchrotron LIS-2.

The radius of the orbit of electrons of this device was $6 \mathrm{~cm}$. The duration of the light impulse of LIS-2 was nearly 0.1 seconds, was exceeded the only known pulsed synchrotron at the time, located in Moscow by approximately a thousand times and was therefore a world record. On the Figure 20 full radiation of the synchrotron LIS-2 is presented.

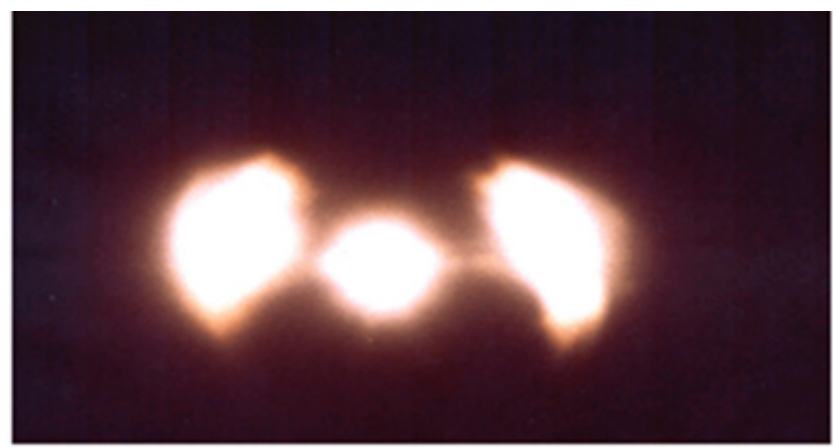

Figure 20. Full radiation from synchrotron LIS-2. The side spots are reflections from the wall of the pipe.

We were about to bring to an end working on a laboratory synchrotron with electrons of similar orbit, but with superconducting magnets (Figure 21), however due to the lost financing as a result of the big changes in the society the work remained uncompleted.

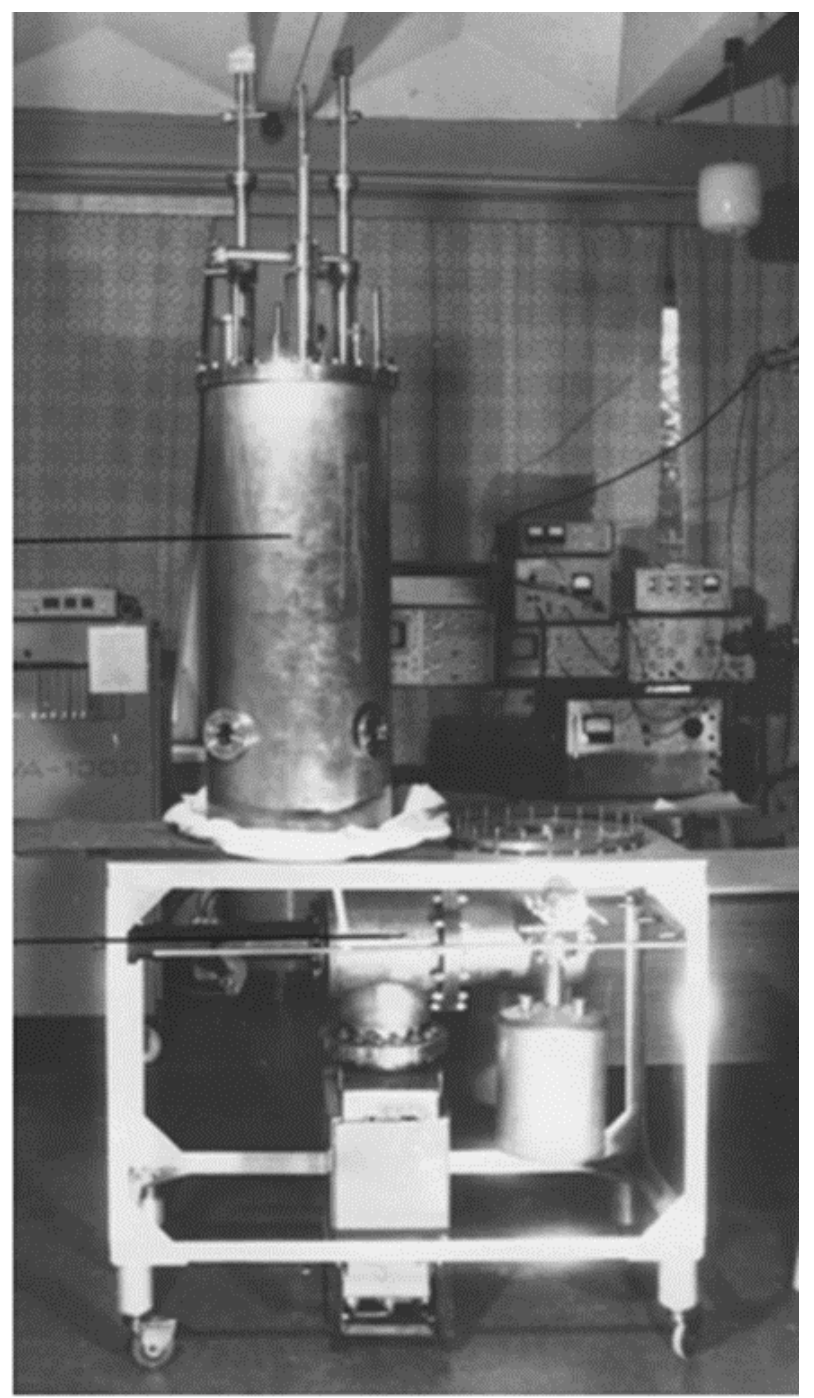

Figure 21. The main part of the laboratory synchrotron with superconducting magnets.

\section{Conclusions}

During its two hundred years of activities the Tartu Observatory has achieved results that go down as significant in the history of science. The DED had the opportunity to actively participate in several research programmes of the Soviet Union during the initial years of the space era. In collaboration with MŠAI, CrAO and MIS we initiated the building of an astronomical orbital observatory with several telescopes that was launched to the Earth's orbit on April 18, 1968, where it worked smoothly. It was the world's first apparatus of its kind in the world. The DED built the world's first diffraction grating double ultraviolet vacuum monochromator in the world. The DED also built the best laboratory pulsed synchrotron at the time. 
The Department of Equipment Development was closed in spring 1993 due to the lack of science financing.

The space work in Estonia continued only about 45 years after the first orbital astronomical observatory was launched from Kapustin Yar when ESTCube-1 was launched to the orbit from South America in the spring of 2013.

\section{Acknowledgements}

I would like to thank all my quondam colleagues, with whom we worked over many years in the Estonian Academy of Sciences structures devising new scientific apparatuses. I would like to express my utmost gratitude to Silvia Leppik, Aime Tootsi, Riho Nymmik, Arved-Ervin Sapar, Neeme-Rein Elmet, Rimma Šatskina, Erna Kõiv, Paul Põldoja, Marju Saar, Mare Tasuja, Toomas Pung, Elmo Märtinson, Jüri Lepp, Ants Kalvik, Enok Sein, Robert Kõiv, Karmen Sepp, Maire Türn, Maie Toomsalu, Heiny Lokko, Vera Budzko, Roman Denisov, Tõnu Jõesaar, Anatoli Kuznetsov, Elar Vilt, Kalev Pill, Tiit Lepasaar, Paul Nurm, Allan Paddar, Arno Rõõm, Eero Meier, Taimo Kübbar, Vello Talvere, Valter Putting, Juhan Toomsoo, Aavo Sirk, Roman Mugur, Mati Meos, Enn Erme, Mango Mägi, Jüri Käosaar and Teet Rätsepp for their active participation in creating and studying space technology. I would like to thank the engineer of SCBoEAS Hillar Bachmann, the head of TSU laboratory Arved Tammik, Vladimir G. Kurt and Evgeny K. Sheffer, working for the Moscow Šternberg Astronomical Institute, Andrei V. Bruns and Nikolai A. Dimov working for the Crimean Astrophysical Observatory, Konstantin K. Sidorin and Vera Arhangelskaya working for S. I. Vavilov State Optical Institute and many others from Moscow, St Petersburg and several other places in the erstwhile Soviet Union for content-rich discussions! I would also like to thank Vivian Unt for the help in developing this article. It is thanks to the extensive collaboration that the DED succeeded in contributing to the building of apparatuses and developing space research in Estonia and the then Soviet Union.

\section{REFERENCES}

[1] https://en.wikipedia.org/wiki/Vega\#Distance

[2] https://en.wikipedia.org/wiki/Ernst_Öpik

[3] T. A. Chubb and H. Friedman. Photon Counters for the Far Ultraviolet, Rev. Sci. Instrum., Vol. 26, No. 5, 493 - 498, 1955.

[4] P. D. Johnson. Improved Concave Grating Mounting, Rev. Sci.
Instrum., Vol. 28, 833 - 834, 1957.

[5] V. M. Tiit. Dvuhlutševoi vakuumnyi monohromator DVM-1 s kompensatsionnoi registriruyuštšei sistemoi, Žurnal prikladnoi spektroskopii, Vol. 7, No. 2, 278 - 283, 1967.

[6] V. Tiit. Kahekiireline topelt vaakummonokromaator TVM-3 spektripiirkonnale 100-220 nm, Eesti NSV TA Toim., Füüs. Mat. seeria, Vol. XVI, No. 3, 393 - 396, 1967.

[7] V. Tiyt. The Double Vacuum Monochromator for the Wavelength in the Range of 100-300 nm, Vth Internat. Conf. on Vacuum Ultraviolet Radiation Physics, Montpellier, France, $80-82,1977$.

[8] V. G. Kurt, S. B. Dostovalov and E. K. Sheffer. The Venus Far Ultraviolet Observations with Venera 4, Journal of the Atmospheric Sciences, Vol. 25, 668 - 671, 1968.

[9] V. P. Beljaev, V. G. Kurt, A. S. Melioranskii, A. S. Smirnov, L. S. Sorokin, V. M. Tiit. Nabludeniya ultrafioletovogo izlutšeniya s mežplanetnoi stantsii „Venera 5" i ,Venera - 6", Kosm. issledovaniya, Vol. VIII, No. 5, 740 $-749,1970$.

[10] N. A. Dimov. Preliminary note on the astronomical satellite Kosmos 215, Ultraviolet Stellar Spectra and Ground-Based Observations, eds. L. Houziaux and H.-E. Butler, Lunteren, Netherlands, IAU Symp. 36, 138, 1970.

[11] http://nssdc.gsfc.nasa.gov/nmc/spacecraftDisplay.do?id=1966 $-031 \mathrm{~A}$

[12] http://nssdc.gsfc.nasa.gov/nmc/spacecraftDisplay.do?id=1968 $-110 \mathrm{~A}$

[13] V. B. Vasilyev, G. M. Gretško, A. A. Gubarev, B. M. Stolberg, V. M. Tiit, N.-R. A. Elmet, R. V. Šatskina. Izmerenie ultrafioletovogo izlutšenya Luny i verhnei atmosfery Zemli s orbitalnoi stantsii „Saljut - 4”, Sb., pod red. L. Riives, Optitšeskiye issledovaniya atmosfery, polarnyh sijanii i serebristyh oblakov s borta orbitalnoi nautšnoi stantsii „Salut - 4”, Tartu, Estonia, 145 - 154, 1977.

[14] R. A. Denisov, V. Tiit, E. Feldbakh. Spectrometer for measuring transmission spectra, United States Patent No. 4,546,256. Oct. 8, 1985.

[15] V. Tiit, R. A. Denisov. Double vacuum monochromator and spectrophotometer, Nuclear Instruments and Methods in Physics Research, Section A, Vol. A 261, Issue 1 - 2, 99 100, 1987.

[16] V. Tiit. Kompaktne vaakummonokromaator, Eesti TA Toim., Füüs. Matem. seeria, Vol. 38, No. 4, 446 - 449. 1989.

[17] A. S. Kuznetsov, E. E. Vilt, V. M. Tiit, K. E. Pill i A. H. Haamer. Istotšnik synhrotronnogo izlutšeniya, Avt. sv. SSSR, No. 1723981, 1991.

[18] A. S. Kuznetsov, H.-R. Bachman, A. Haamer, M. Piilma, K. Pill, K. K. Sidorin, A.-A. Tammik, V. Tiit and E. Vilt. On devising pulsed synchrotron radiation source for laboratory applications, Nucl. Instrum. Methods, Vol. A 261, Issues 1 $2,58-59,1987$. 